Для цитирования: Давидовский С.В., Ибрагимова Ж.А., Игумнов С.А., Костюк Д.Д., Мещеряков Ю.В., Стефанин А.Л. Клинико-психологические и социально-демографические особенности суицидального поведения населения Минска (Республика Беларусь). Сибирский вестник психиатрии и наркологии. $2020 ; 3$ (108): 102113. https://doi.org/10.26617/1810-3111-2020-3(108)-102-113

\title{
Клинико-психологические и социально-демографические особенности суицидального поведения населения Минска (Республика Беларусь)
}

\section{Давидовский С.В.1, Ибрагимова Ж.А.2, Игумнов С.А. ${ }^{3}$, Костюк Д.Д.4, Мещеряков Ю.В.1, Стефанин А.Л.1}

\author{
${ }^{I}$ Белорусская медицинская академия последипломного образования \\ Республика Беларусь, 220013, Минск, ул. Петруся Бровки, д. 3, к.3 \\ ${ }^{2}$ Белорусский государственный медицинский университет \\ Республика Беларусь, 220116, Минск, пр. Дзержинского, д. 83 \\ ${ }^{3}$ Национальный научный центтр наркологии - филиал ФГБУ \\ «Национальный медицинский исследовательский центр психиатрии и наркологии им. В.П. Сербского» \\ Россия, 119034, Москва, Кропоткинский пер., д. 23 \\ ${ }^{4}$ Вроилавский государственный университет, Институт психологии \\ Польша, 50-137, Врочлав, площадь Университетская, 1
}

\section{PEЗЮME}

Актуальность проблемы. В настоящее время остается актуальным поиск надежных индикаторов риска совершения суицида, что делает важным аспект изучения причин и условий возникновения суицидального поведения. Цель: определить статистически значимые клинико-психологические факторы и социальнодемографические особенности, взаимосвязанные с выраженной мотивацией к совершению суицида. Материал и методы. На основании результатов 10-летнего мониторинга суицидального поведения жителей Минска из основной группы респондентов были сформированы две группы суицидального риска: 1) группа лиц, использовавших нелетальные способы самоповреждающего поведения (условно названная ГЛИНСС), 2) группа лиц, использовавших высоколетальные способы самоповреждения (ГЛИВС). К группе сравнения отнесены лица, у которых было диагностировано расстройство адаптации (шифр по МКБ-10 F43.2), ранее не совершавшие суицидальных попыток. Значимость для бинарных показателей оценивалась по критерию Пирсона $\left(\chi^{2}\right)$, для количественных показателей - по критерию Краскала-Уоллиса $(\mathrm{H})$, межгрупповые различия оценивались по критерию Манна-Уитни (U). Взаимосвязи между социально-психологическими факторами и мотивацией к совершению суицида определялись посредством коэффициента корреляции Спирмена (r) с использованием языка программирования Руthon. Результаты. Наиболее значимым фактором, взаимосвязанным с выраженной мотивацией к совершению самоубийства, явился способ совершения суицида $\left(\mathrm{r}_{\mathrm{s}}=-0,68\right)$. Установлено, что пограничный уровень значимости $\left(\mathrm{r}_{\mathrm{s}}=0,28\right)$ имели два фактора: 1$)$ фактор наличия психических расстройств, обусловленный у мужчин потреблением алкоголя, у женщин - эмоциональными нарушениями депрессивного спектра, 2) фактор образования $\left(\mathrm{r}_{\mathrm{s}}=0,28\right)$. Для лиц групп суицидального риска (ГЛИНСС и ГЛИВС) характерно воспитание в неполной семье, проживание в одиночестве или неполных семьях, наличие среднего или среднеспециального образования. В группе ГЛИВС выявлены определенные личностные черты (возбудимость у мужчин и циклотимия у женщин). Выводы. Наиболее значимым фактором, взаимосвязанным с выраженной мотивацией к совершению суицида, был способ суицидальных действий. На границе статистической значимости находились фактор наличия диагноза психического расстройства и фактор образования. Социальные условия проживания и индивидуальные особенности личности были значимыми факторами для групп суицидального риска, но не были взаимосвязаны с выраженной мотивацией к совершению суицида.

Ключевые слова: суицид, парасуицид, индикаторы риска совершения суицида, способ суицида, население Белоруссии, коэффициент корреляции Спирмена. 


\section{ВВЕДЕНИЕ}

Смертность от намеренного самоповреждения является актуальной медико-социальной проблемой современности, представляя угрозу для большинства стран мира. Согласно данным Всемирной организации здравоохранения, смертность в возрасте от 15 до 29 лет составляет 8,5\% всех смертей, являясь второй по значимости причиной смертности после дорожно-транспортных происшествий [1].

Проблема суицидального поведения актуальна как для Республики Беларуси, так и для Российской Федерации (РФ) на протяжении последних десятилетий. В 1990-е годы среди государств, ранее входивших в состав СССР, по уровню суицидов РФ и Республика Беларусь занимали соответственно 4-е и 5-е места, следуя после республик Прибалтики Латвии, Литвы и Эстонии [2]. На фоне социальной стабилизации в период 1995-2014 гг. в России произошло снижение частоты суицидов в 2,2 раза [3]. Сходная динамика показателей суицидального поведения населения отмечена и в Беларуси [4].

Однако, несмотря на актуальность данной проблемы, исследования, активно проводившиеся в СССР в период 1980-х гг., в настоящее время на постсоветском пространстве единичны и фрагментарны [5]. Между тем знание общих закономерностей и механизмов формирования суицидального поведения необходимо не только в контексте научного познания, но и для разработки и осуществления государственных программ по профилактике суицидов с учетом национальной специфики в конкретной стране мира $[6,7]$.

Это делает важным изучение причин и условий возникновения суицидального поведения, выявления факторов и групп риска суицида с целью повышения эффективности мероприятий, направленных на предикцию суицидов.

\section{ЦЕЛЬ ИССЛЕДОВАНИЯ}

Определить статистически значимые клиникопсихологические факторы и социальнодемографические особенности, взаимосвязанные с выраженной мотивацией к совершению суицида.

\section{МАТЕРИАЛЫ И МЕТОДЫ}

Выборка исследования - население Минска На основании данных мониторинга суицидальной активности жителей Минска, выполненного за 10летний период (с 2004 г. по 2014 г.) были определены социально-демографические характеристики и клинические закономерности, характерные для лиц, совершивших завершенный суицид и парасуицид. Всего было проанализировано 15996 случаев парасуицидов и 2355 случаев суицидов (суммарно 18 351).
На основании полученных данных было установлено, что среди совершивших парасуицид, преобладали лица в возрасте 20-39 лет (не менее $60 \%$ от общего количества лиц, совершивших самоповреждение, от 59,7\% в 2011 г. до 65,4\% в 2008 г.), соотношение мужчин к женщинам было равномерным - 1:1. Среди совершивших завершенный суицид преобладали лица мужского пола в возрастном промежутке 26-60 лет (от 54\% в 2006 г. до 66,6\% в 2013 г.), соотношение мужчин к женщинам в данном возрастном диапазоне составило 4:1. Наиболее распространенными способами самоповреждения у лиц, совершивших парасуицид, являлись медикаментозное отравление и поверхностные повреждения вен и кожи, как правило, на фоне алкогольного опьянения. Данные методы самоповреждения отмечались не менее чем в $65 \%$ случаев, вне зависимости от года наблюдения (от 65\% в 2014 г. до 95\% в 2010 г. и 2009 г.). Наиболее распространенным способом ухода из жизни лиц, совершивших завершенный суицид, было самоповешение (от 76,9\% в 2012 г. до 95,5\% в 2008 г.).

На основании выявленных закономерностей были сформированы две группы респондентов: 1) группа лиц, использовавших нелетальные способы самоповреждения (далее - ГЛИНСС), 2) группа лиц, использовавших высоколетальные способы самоповреждения (далее - ГЛИВС), которые могли привести к смерти в случае несвоевременного оказания им медицинской помощи. В группу сравнения (далее - ГС) вошли лица, у которых было диагностировано расстройство адаптации (F43.2 по МКБ-10), но при этом суицидальных попыток и действий не совершавшие. Данная группа по своим социальнодемографическим характеристикам соответствовала ГЛИВС.

Всего в исследовании приняли участие 160 человек. ГЛИНСС состояла из 80 человек, из них 40 мужчин и 40 женщин, лица в возрасте 20-39 лет составили большинство - 62,5\%. ГЛИВС и ГС включали по 40 человек, соотношение женщин и мужчин в данных группах было 1:3,4 (31 - лица мужского пола, 9 женщин, преобладали лица в возрасте 26-60 лет - 65\%), что соответствовало выборке лиц, совершивших суицид.

Исследование проводилось на базе отделения токсикологии городской клинической больницы скорой медицинской помощи г. Минска и государственного учреждения «Республиканский научно-практический центр психического здоровья» Минздрава Беларуси в отделениях для лечения кризисных состояний. Пациенты включались в исследование после получения письменного согласия. 
При проведении исследования фиксировались социально-демографические данные, оценивался уровень перенесенного стресса по шкале стрессовых событий Холмса-Рея, определялась выраженность депрессивной симптоматики по шкале Монтгомери-Асберга, выраженность мотивации к совершению суицида по 10-балльной аналоговой шкале. Индивидуально-характерологические особенности суицидентов определялись с использованием личностного опросника Г. Айзенка по определению типа темперамента и теста-опросника Г. Шмишека и К. Леонгарда для диагностики типа акцентуации. Значимость дихотомических показателей оценивалась по критерию Пирсона $\chi^{2}$, количественных показателей - по критерию Краскала-Уоллиса Н, межгрупповые различия - по критерию Манна-Уитни U.
Для оценки непараметрических данных использовалась запись Me [LQ; UQ]. Выраженность взаимосвязи между клинико-психологическими факторами и мотивацией к совершению суицида оценивалась посредством коэффициента корреляции Спирмена (r) с использованием языка программирования Руthon, что позволило отказаться от использования дорогостоящих коммерческих статистических пакетов.

\section{РЕЗУЛЬТАТЫ}

Как представлено в таблице 1, в ГС преобладали лица $(\mathrm{n}=38,95 \%)$ с диагнозом «Смешанная тревожная и депрессивная реакция, обусловленная расстройством адаптации» (F43.22); только в 2 случаях (5\%) выставлен иной диагноз «Смешанное расстройство эмоций и поведения» (F43.25).

Т а б л и ц а 1. Клинико-нозологическая структура психических расстройств в группах респондентов

\begin{tabular}{|c|c|c|c|c|c|c|}
\hline \multirow{2}{*}{$\begin{array}{c}\text { Диагноз } \\
\text { по МКБ-10 }\end{array}$} & \multirow{2}{*}{$\begin{array}{c}\Gamma C \\
(n=40)\end{array}$} & \multirow{2}{*}{$\begin{array}{c}\text { ГЛИВС } \\
(\mathrm{n}=40)\end{array}$} & \multicolumn{4}{|c|}{ ГЛИНСС (n=80) } \\
\hline & & & $\begin{array}{c}\text { Мужчины } \\
(\mathrm{n}=40)\end{array}$ & $\begin{array}{c}\text { Женщины } \\
(\mathrm{n}=40)\end{array}$ & $\begin{array}{l}\text { Всего } \\
(\mathrm{n}=80)\end{array}$ & $\begin{array}{l}\text { Статистическая } \\
\text { значимость, } \chi^{2}\end{array}$ \\
\hline F43.22 & 38 & & & 1 & & \\
\hline F43.25 & 2 & 15 & 9 & 20 & 29 & $\chi^{2}=6,66 ; p=0,01$ \\
\hline F10.24 & & 8 & 9 & 3 & 12 & $\mathrm{p}^{*}=0,06$ \\
\hline $\mathrm{F} 43.25+\mathrm{F} 10.21$ & & 8 & 5 & 2 & 7 & $\mathrm{p}^{*}=0,62$ \\
\hline$F 06.31+F 10.24$ & & 2 & & 1 & 1 & \\
\hline F61 & & 1 & 1 & & 1 & \\
\hline F06.32 + F06.8 & & 3 & 1 & 1 & 1 & \\
\hline F23.0 & & & 1 & & 1 & \\
\hline F25.0 & & & & 1 & & \\
\hline $\mathrm{F} 43.22+\mathrm{F} 10.24$ & & & 1 & & 1 & \\
\hline $\mathrm{F} 31.1+\mathrm{F} 10.24$ & & & 1 & 1 & 2 & \\
\hline F32.1 & & 2 & 2 & 5 & 7 & \\
\hline $\mathrm{F} 32.2+\mathrm{F} 10.2$ & & & & 1 & & \\
\hline F11.3 & & & 1 & & 1 & \\
\hline F23.1 & & & 1 & & 1 & \\
\hline $\mathrm{F} 41.0+\mathrm{F} 41.2$ & & & 1 & 2 & 1 & \\
\hline $\mathrm{F} 43.21+\mathrm{F} 10.24$ & & & 1 & & 1 & \\
\hline F43.21 & & 1 & & & & \\
\hline $\mathrm{F} 60.31+\mathrm{F} 10.24$ & & & & & & \\
\hline F10.1 & & & 4 & 1 & 4 & \\
\hline $\mathrm{F} 10.3+\mathrm{F} 10.52$ & & & 2 & & 2 & \\
\hline$F 15.0+F 10.24$ & & & & 1 & 1 & \\
\hline
\end{tabular}

П р и м е ч а н и е. *-точный критерий Фишера (F).

У лиц, входящих в ГЛИВС, более чем в трети случаев $(\mathrm{n}=15,37,5 \%)$ встречался диагноз «Смешанное расстройство эмоций и поведения» (F43.25) в отличие от ГC, где он был самым немногочисленным. Кроме того, в ГЛИВС с одинаковой частотой $(\mathrm{n}=8,20,0 \%)$ диагностировано «Употребление вещества в настоящее время (активная зависимость)» и сочетанное течение «Смешанного расстройства эмоций и поведения» и «В настоящее время воздержание, но в условиях, исключающих употребление». Другие диагнозы были зафиксированы в ГЛИВС в единичных случаях.
В ГЛИНСС большая часть респондентов имела диагноз «Смешанное расстройство эмоций и поведения» $(\mathrm{n}=29,36,3 \%)$, т.е. схожая частота встречаемости данного диагноза с ГЛИВС. Вторым по частоте выявляемости был диагноз «Употребление вещества в настоящее время (активная зависимость)» $(\mathrm{n}=12,15 \%)$. С одинаковой частотой в ГЛИНСС встречались как сопутствующее течение «Смешанного расстройства эмоций и поведения» и «В настоящее время воздержание, но в условиях, исключающих употребление», так и «Депрессивный эпизод средней степени $(\mathrm{n}=7$, 
8,75\%), причем с преобладанием у мужчин по сравнению с женщинами. Для остальных диагнозов характерна минимальная доля встречаемости. Диагностированный в ГЛИНСС «Депрессивный эпизод средней степени» преобладал у лиц женского пола (5 случаев из 7 диагностированных $8,75 \%$ от общего числа обследованных.

T.е. для всех групп респондентов было характерно преобладание лиц, имеющих не только основной, но и сопутствующий диагноз, обусловленный потреблением психоактивных веществ. Ранее проведенный нами анализ особенностей суицидального поведения среди жителей г. Минска за период с 2007 г. по 2014 г. так же позволил обнаружить наличие алкогольного опьянения у 43,5\% лиц мужского пола, совершивших суицид [8].

Однако статистически значимых гендерных различий в ГЛИНСС по диагнозу «Зависимость от психоактивных веществ» $\left(\chi^{2}=6,66, p=0,06\right)$, которая чаще диагностировалась у лиц мужского пола, не обнаружено. Данный факт может быть объяснен сравнительно небольшим количеством респондентов, включенных в сравнительный анализ. Статистически значимые гендерные различия $\left(\chi^{2}=6,66 ; p=0,01\right)$ в ГЛИНСС были получены по наличию диагноза «Расстройство приспособительных реакций» (F43.2), причем снижение адаптационной приспособляемости статистически значимо чаще определялось у лиц женского пола.
Далее было проведено обследование респондентов по оценке степени выраженности депрессии с применением шкалы Монтгомери-Асберга. Наиболее высокая выраженность депрессивной симптоматики отмечалась в ГЛИВС - 22,0 балла $[16,0 ; 26,0]$, наиболее низкая выраженность зафиксирована в ГЛИНСС - 15,5 балла $[10,0 ; 21,0]$. В ГС выраженность депрессии занимала промежуточную позицию - 17,0 балла $[13,0 ; 22,0]$, статистически значимые различия $(\mathrm{p}=0,03)$ были выявлены только между респондентами ГЛИВС и ГЛИНСС. Следует отметить, что распространенность расстройств настроения депрессивного спектра в ГЛИНСС (суммарно $\mathrm{n}=7,8,75 \%$ от общего числа обследованных) соответствовала результатам исследований определения риска суицида у депрессивных больных, не требующих лечения в условиях психиатрического стационара (в диапазоне от 7,3\% до 10,8\%) [9].

Как показано в таблице 2, в двух группах ГЛИНСС и ГЛИВС преобладали незамужние, холостые, разведенные, вдовствующие: соответственно суммарно в ГЛИНСС - $\mathrm{n}=55,77,5 \%$, в ГЛИВС - n=28, 65,0\%. Выявленные гендерные различия в ГЛИНСС по социальному статусу респондентов не были статистически значимы. В ГС, напротив, в отличие от двух других групп преобладали состоящие в браке $(\mathrm{n}=25,72,5 \%$ обследованных), которые проживали либо в семьях, либо с партнером $(70,0 \%)$.

\section{Т а б л и ц а 2. Распределение респондентов обследованных групп по социальному статусу}

\begin{tabular}{|l|c|c|c|c|c|c|}
\hline Социальный статус & \multirow{2}{*}{$\begin{array}{c}\text { ГС } \\
(\mathrm{n}=40)\end{array}$} & $\begin{array}{c}\text { ГЛИВС } \\
(\mathrm{n}=40)\end{array}$ & $\begin{array}{c}\text { Мужчины } \\
(\mathrm{n}=40)\end{array}$ & $\begin{array}{c}\text { Женщины } \\
(\mathrm{n}=40)\end{array}$ & $\begin{array}{c}\text { Всего } \\
(\mathrm{n}=80)\end{array}$ & $\begin{array}{c}\text { Статистическая } \\
\text { значимость, } \chi^{2}\end{array}$ \\
\hline Холост/не замужем & 5 & 13 & 17 & 11 & 28 & $\chi^{2}=1,48, \mathrm{p}=0,22$ \\
\hline Женат/замужем & 25 & 12 & 11 & 14 & 25 & $\chi^{2}=1,15, \mathrm{p}=0,29$ \\
\hline Гражданский брак & 2 & 2 & 4 & 3 & 7 & \multirow{2}{*}{$\chi^{2}=0,21, \mathrm{p}=0,65$} \\
\cline { 1 - 5 } Разведен & 5 & 6 & 7 & 7 & 14 & \\
\hline Вдовец/вдова & 3 & 7 & 1 & 5 & 6 & \\
\hline
\end{tabular}

Воспитание в неполных семьях чаще отмечалось среди респондентов ГЛИВС $(\mathrm{n}=11,27,5 \%)$ по сравнению с группами ГЛИНСС $(\mathrm{n}=7,17,5 \%)$ и ГС $(\mathrm{n}=2,5 \%)$.

Лица, имеющие высшее образование, преобладали в ГС (n=27, 67,5\%). Лица со средним образованием составили большинство в ГЛИВС $(\mathrm{n}=15,37,5 \%)$ и ГЛИНСС $(\mathrm{n}=37,46,25 \%)$, незначительно меньшая доля в этих группах приходилась на лиц со среднеспециальным образованием: ГЛИВС - n=14, 35\%, ГЛИНСС - n=34, 42,5\%. Статистически значимых гендерных различий между респондентами ГЛССРС по данному показателю выявлено не было.

\section{Т а б л и ц а 3. Распределение респондентов обследованных групп по трудовой занятости}

\begin{tabular}{|l|c|c|c|c|c|c|}
\hline Социальный статус & \multirow{2}{*}{$\begin{array}{c}\text { ГС } \\
(\mathrm{n}=40)\end{array}$} & $\begin{array}{c}\text { ГЛИВС } \\
(\mathrm{n}=40)\end{array}$ & $\begin{array}{c}\text { Мужчины } \\
(\mathrm{n}=40)\end{array}$ & $\begin{array}{c}\text { Женщины } \\
(\mathrm{n}=39)\end{array}$ & $\begin{array}{c}\text { Всего } \\
(\mathrm{n}=79)\end{array}$ & $\begin{array}{c}\text { Статистическая } \\
\text { 3начимость, } \chi^{2}\end{array}$ \\
\hline Работающие & 25 & 22 & 25 & 19 & 44 & $\chi^{2}=1,88$ \\
$\mathrm{p}=0,17$ & \\
\hline Неработающие & 15 & 16 & 12 & 16 & 28 & 6 \\
\hline Пенсионеры & - & 2 & 2 & 4 & 1 & \\
\hline Учащиеся & - & - & 1 & - & & \\
\hline
\end{tabular}


Исходя из приведенных в таблице 3 данных, среди респондентов всех групп наиболее значимая доля приходилась на работающих: $Г \mathrm{C}-\mathrm{n}=25$, 62,5\%; ГЛИВС - n=22, 55,0\%; ГЛИНСС - n=44, $55,7 \%$. Статус неработающих варьировал в пределах от более трети до немногим менее половины респондентов в каждой из групп: ГС - n=15, $37,5 \%$; ГЛИВС - n=16, 45,0\%; ГЛИНСС - n=28, $44,3 \%$. Численность пенсионеров и учащихся во всех группах была минимальной. Статистически значимых различий по данному показателю между мужчинами и женщинами в ГЛССРС выявлено не было $\left(\chi^{2}=1,88, \mathrm{p}=0,17\right)$.

Как продемонстрировано в таблице 4, среди респондентов ГС преобладали лица, имеющие доход выше минимального прожиточного уровня в Республике Беларусь (в долларовом эквиваленте): $160-320 \$-\mathrm{n}=10,25,0 \%$; 320-500 $\$-\mathrm{n}=10$, $25,0 \%$ ), свыше $500 \$-\mathrm{n}=6,15,0 \%$. В ГЛИВС преобладали респонденты с доходом 100-160 \$ (n=16, $40,0 \%)$; и 160-320 \$ $(\mathrm{n}=10,25,0 \%)$. В ГЛИНСС практически треть респондентов имела доход $160-320 \$(\mathrm{n}=26,32,9 \%)$, у четверти респондентов доход составлял 100-160\$ (n=21, 26,6\%). Вместе с тем во всех группах с незначительной разницей выявлены респонденты с отсутствием стабильного дохода: ГС $-\mathrm{n}=3,7,5 \%$; ГЛИВС $-\mathrm{n}=4,10,0 \%$; ГЛИНСС - n=8, 10,1\%. Следует отметить, что в ГЛИНСС гендерные различия по уровню доходов были статистически значимы.

\section{Т а б л и ц а 4. Распределение респондентов обследованных групп по уровню дохода}

\begin{tabular}{|c|c|c|c|c|c|c|}
\hline \multirow[t]{2}{*}{ Уровень дохода } & \multirow{2}{*}{$\begin{array}{c}\Gamma C \\
(n=40)\end{array}$} & \multirow{2}{*}{$\begin{array}{c}\text { ГЛИВС } \\
(\mathrm{n}=40)\end{array}$} & \multicolumn{4}{|c|}{ ГЛИНСС $(\mathrm{n}=80)$} \\
\hline & & & $\begin{array}{c}\text { Мужчины } \\
(\mathrm{n}=40)\end{array}$ & $\begin{array}{c}\text { Женщины } \\
(\mathrm{n}=39)^{*}\end{array}$ & $\begin{array}{l}\text { Всего } \\
(n=79)\end{array}$ & $\begin{array}{l}\text { Статистическая } \\
\text { значимость, } \chi^{2}\end{array}$ \\
\hline Стабильный доход отсутствует & 3 & 4 & 5 & 3 & 8 & $\chi^{2}=1,51$ \\
\hline Менее $100 \$$ & 5 & 5 & 3 & 9 & 12 & $\mathrm{p}=0,21$ \\
\hline $100-160 \$$ & 6 & 16 & 10 & 11 & 21 & \\
\hline $160-320 \$$ & 10 & 10 & 13 & 13 & 26 & \\
\hline $320-500 \$$ & 10 & 3 & 6 & 1 & 7 & \\
\hline Более $500 \$$ & 6 & 2 & 3 & 2 & 5 & \\
\hline
\end{tabular}

П р и м е ч а н и е. *- точный критерий Фишера (F).

Проведенный статистический анализ с применением критерия Краскала-Уоллиса (р) выявил статистически значимые различия между группами по шести показателям: наличие диагноза психического/поведенческого расстройства $(\mathrm{p}=0,000)$, способ совершения суицидального действия $(\mathrm{p}=0,000)$, семейный статус $(\mathrm{p}=0,004)$, образование $(\mathrm{p}=0,000)$, условия проживания $(\mathrm{p}=0,023)$ и условия воспитания $(\mathrm{p}=0,029)$. По трем показателям (профессиональный статус, уровень дохода, особенности воспитания) статистически значимые различия не обнаружены (табл. 5).

T а б л и ц а 5. Распределение значимых связей между принадлежностью респондентов к группе и клиническими и социальными характеристиками

\begin{tabular}{|l|c|c|}
\hline \multicolumn{1}{|c|}{ Показатель } & Наличие значимой связи & Значимость по критерию Краскала-Уоллиса \\
\hline Наличие психических расстройств & Есть & $\mathrm{p}=0,000$ \\
\hline Способ совершения суицида & Есть & $\mathrm{p}=0,000$ \\
\hline Семейный статус & Есть & $\mathrm{p}=0,004$ \\
\hline Уровень образования & Есть & $\mathrm{p}=0,000$ \\
\hline Условия проживания & Есть & $\mathrm{p}=0,023$ \\
\hline Профессиональный статус & Нет & $\mathrm{p}=0,613$ \\
\hline Уровень дохода & Нет & $\mathrm{p}=0,085$ \\
\hline Условия воспитания & Есть & $\mathrm{p}=0,029$ \\
\hline Особенности воспитания & Нет & $\mathrm{p}=0,489$ \\
\hline
\end{tabular}

Выполненный межгрупповой анализ с использованием критерия Манна-Уитни выявил различия между группами суицидального риска по двум показателям: мотивация к совершению суицида $(\mathrm{p}=0,000)$ и способ суицида $(\mathrm{p}=0,000)$.

При оценке индивидуальных особенностей личности респондентов использовался личностный опросник определения темперамента Г. Айзенка, который показал преобладание в ГЛИВС лиц с флегматическим темпераментом $(50,0 \%)$, для которых характерна склонность к соблюдению привычных форм поведения и действий, а также наличие трудностей в выработке новых форм поведенческой активности. В ГЛИВС выделялись также лица, имеющие меланхолический темперамент $(\mathrm{n}=12,35,3 \%)$, который преобладал среди респондентов, входящих как в ГС $(\mathrm{n}=21$, $61,7 \%)$, так и в ГЛИНСС (n=26, 35,1\%). В ГС выделялась также группа лиц, имеющих холерический темперамент $(\mathrm{n}=11,27,5 \%)$. 
Т а б л и ц а 6. Распределение респондентов обследованных групп в зависимости от типа темперамента

\begin{tabular}{|l|c|c|c|c|c|c|}
\hline \multirow{2}{*}{ Тип темперамента } & \multicolumn{2}{|c|}{ ГС $(\mathrm{n}=34)$} & \multicolumn{2}{c|}{ ГЛИНС $(\mathrm{n}=71)$} & \multicolumn{2}{c|}{ ГЛИВС $(\mathrm{n}=34)$} \\
\cline { 2 - 7 } & абс. & $\%$ & абс. & $\%$ & абс. & \% \\
\hline Меланхолик & 21 & $61,7 \%$ & 26 & $35,1 \%$ & 12 & $35,3 \%$ \\
\hline Флегматик & 1 & $2,9 \%$ & 20 & $27,0 \%$ & 17 & $50,0 \%$ \\
\hline Холерик & 11 & $27,5 \%$ & 15 & $20,3 \%$ & 4 & $11,8 \%$ \\
\hline Сангвиник & 1 & $2,9 \%$ & 6 & $8,1 \%$ & 1 & $2,9 \%$ \\
\hline \multicolumn{1}{|c|}{ Всего } & 34 & $100 \%$ & 71 & $100 \%$ & 34 & $100 \%$ \\
\hline
\end{tabular}

Отличие итоговых показателей численности групп в таблице 6 от других таблиц в тексте обусловлено тем, что из проводимого анализа были исключены лица, которые по шкале «Лжи» набрали 5 баллов и более.

Таким образом, по мере выраженности жизнеопасности суицидальной попытки и мотивации к совершению суицида доля лиц с флегматическим темпераментом возрастала от 2,9\% в ГС до $28,2 \%$ в ГЛИНСС и до $50 \%$ в ГЛИВС, при этом полученные различия были статистически значимы.
Кроме того, статистически значимые различия были обнаружены также по показателю нейротизма $(\mathrm{p}=0,003)$ и по трем индивидуальным характеристикам личности обследованных респондентов: застреваемость $(\mathrm{p}=0,006)$, возбудимость $(p=0,032)$, циклотимия $(p=0,013)$ Указанные индивидуально-характерологические особенности оценивались нами посредством привлечения к обследованию теста-опросника Г. Шмишека и К. Леонгарда, с помощью которого возможно оценить 10 типов акцентуаций характера.

Т а б л и ц а 7. Распределение значимых связей между принадлежностью респондентов к группе и характеристиками личности

\begin{tabular}{|l|c|c|}
\hline \multicolumn{1}{|c|}{ Показатель } & Наличие значимой связи & Значимость по критерию Краскала-Уоллиса \\
\hline Темперамент & Есть & $\mathrm{p}=0,002$ \\
\hline Интроверсия-экстраверсия & Нет & $\mathrm{p}=0,183$ \\
\hline Нейротизм & Есть & $\mathrm{p}=0,003$ \\
\hline Демонстративность & Нет & $\mathrm{p}=0,854$ \\
\hline Застреваемость & Есть & $\mathrm{p}=0,006$ \\
\hline Педантичность & Нет & $\mathrm{p}=0,032$ \\
\hline Возбудимость & Есть & $\mathrm{p}=0,589$ \\
\hline Гиперактивность & Нет & $\mathrm{p}=0,013$ \\
\hline Циклотимия & Есть & $\mathrm{p}=0,625$ \\
\hline Тревожность & Нет & $\mathrm{p}=0,106$ \\
\hline Экзальтированость & Нет & $\mathrm{p}=0,898$ \\
\hline Эмотивность & Нет & $\mathrm{p}=0,200$ \\
\hline Дистимия & Нет & \\
\hline
\end{tabular}

Обследованные респонденты мужского пола, входившие в группы ГС и ГЛИВС, статистически значимо не различались по показателю застрева- емости в отличие от показателей нейротизма и возбудимости (табл. 8).

Т а б л и ц а 8. Распределение респондентов мужского пола групп ГЛИВС

и ГС в соответствии с показателями нейротизма, застревания, возбудимости

\begin{tabular}{|l|c|c|c|}
\hline \multicolumn{1}{|c|}{ Показатель } & Критерий Манна-Уитни (U) & Критерий Z & Критерий достоверности Стьюдента (p) \\
\hline Нейротизм & 213 & $-2,78$ & $\mathrm{p}=0,005$ \\
\hline Застревание & 306 & $-1,21$ & $\mathrm{p}=0,231$ \\
\hline Возбудимость & 189 & $-3,18$ & $\mathrm{p}=0,001$ \\
\hline
\end{tabular}

При сравнении групп по показателю циклотимии выявленные различия не имели статистической значимости (p=0,498), однако между ГЛИВС и ГЛИНСС различия были статистически значимы $(\mathrm{p}=0,017)$. При этом у лиц женского пола не было обнаружено статистически значимых межгрупповых различий между группами ГЛИВС и ГЛИНСС, ГЛИВС и ГС, ГС и ГЛИНСС по трем сравниваемым показателям: нейротизм, застреваемость и возбудимость (рис. 1). 

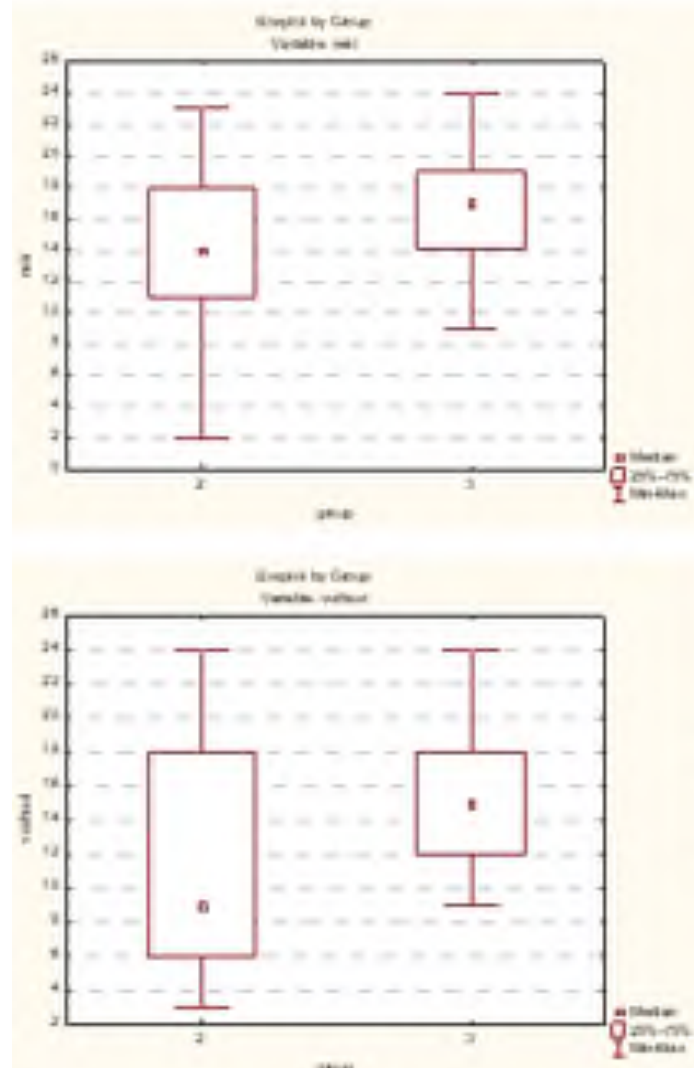

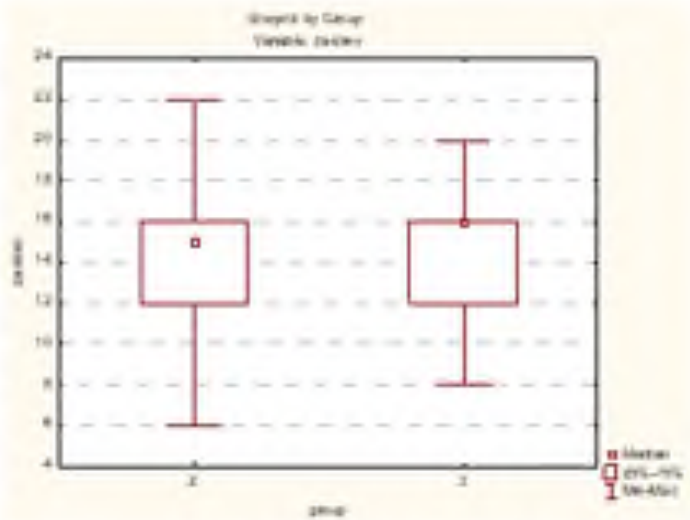

\begin{tabular}{|c|c|c|c|c|}
\hline \multirow[b]{2}{*}{ variable } & \multicolumn{4}{|c|}{$\begin{array}{l}\text { Mann-Whitney U Test }(\mathrm{d}-12-09-1913 \mathrm{c} \\
\text { By variable group } \\
\text { Marked tests are significant at } \mathrm{p}<, 050\end{array}$} \\
\hline & $\begin{array}{c}\text { Rank Sum } \\
\text { Group } 1\end{array}$ & $\begin{array}{c}\text { Rank Sum } \\
\text { Group } 2\end{array}$ & $U$ & \\
\hline neir & 1018.000 & 1397,000 & 388,0000 & -2 \\
\hline zastrav & 1097,500 & 1248,500 & 502,5000 & -0 \\
\hline vozbud & 940,000 & 1406,000 & 345,0000 & -2 \\
\hline
\end{tabular}

Р и с у н о к 1. Сравнительное распределение показателей нейротизма, застревания и возбудимости у респондентов женского пола

Таким образом, в отношении респондентов ГЛИВС были выявлены статистически значимые различия по чертам характера, связанным с перепадами настроения, повышенной раздражительностью и агрессивностью. Для таких лиц, как правило, характерны конфликтность, плохая уживчивость в коллективе, низкий уровень самоконтроля в сфере эмоциональных реакций и отношений. В процессе проведения клинического опроса данные характерологические особенности постоянно прослеживались у лиц, совершивших жизнеопасные методы самоповреждения, с высокой мотивацией на совершение суицида (более 8 баллов по шкале выраженности мотивации к совершению суицида). В дальнейшем статистический анализ проведен с использованием коэффициента корреляции Спирмена $\left(\mathrm{r}_{\mathrm{s}}\right)$.

При расчете этого показателя применялся язык программирования Python из библиотеки Scikitlearn, что позволит в будущем разработать систему принятия решений на основе нейронных сетей.

В ходе дальнейшего анализа по шкале выраженности суицидальной мотивации были выделены 2 группы лиц с определенным уровнем мотивации совершения суицида: 8 баллов и менее 8 баллов. Это позволило выявить как положительные, так и отрицательные взаимозависимо- сти, обусловленные высоким уровнем мотивации на совершение суицида. К регистру положительных связей относился фактор наличия диагноза психического или поведенческого расстройства, который характеризовался пограничным уровнем значимости $\left(\mathrm{r}_{\mathrm{s}}=0,28\right)$, к отрицательным связям способ суицида $\left(\mathrm{r}_{\mathrm{s}}=-0,68\right)$ и фактор образования на уровне пограничной значимости $\left(\mathrm{r}_{\mathrm{s}}=-0,28\right)$. Другие показатели имели значения в диапазоне 2 и менее (пол, гиперактивность, возбудимость, стресс, тип темперамента, экзальтированностьинтроверсия, семейный статус), что свидетельствовало о незначительной корреляционной взаимосвязи данных социально-психологических факторов с мотивацией к совершению суицида.

Установлено, что выраженность взаимосвязи с мотивацией к совершению суицида была различной в зависимости от пола. У лиц женского пола отмечалась умеренная прямая корреляционная взаимосвязь с выраженностью расстройств депрессивного спектра $\left(\mathrm{r}_{\mathrm{s}}=0,36\right)$, умеренная обратная корреляционная взаимосвязь со способом суицида $\left(\mathrm{r}_{\mathrm{s}}=-0,58\right)$ и уровнем дохода $\left(\mathrm{r}_{\mathrm{s}}=-0,4\right)$. Пограничный уровень обратной корреляционной взаимосвязи с мотивацией к совершению суицида был отмечен в отношении фактора образования $\left(r_{\mathrm{s}}=-0,28\right)$. 
У лиц мужского пола отмечалась умеренная прямая корреляционная взаимосвязь с мотивацией к совершению суицида двух факторов: тип темперамента $\left(\mathrm{r}_{\mathrm{s}}=0,37\right)$, наличие диагноза психического или поведенческого расстройства $\left(r_{s}=0,36\right)$. Умеренная обратная корреляционная взаимосвязь отмечалась со способом суицида $\left(\mathrm{r}_{\mathrm{s}}=-\right.$ $0,68)$. На уровне пограничной степени значимости находился фактор образования $\left(\mathrm{r}_{\mathrm{s}}=-0,26\right)$.

Проведенное исследование продемонстрировало, что для лиц, входящих в группы суицидального риска (ГЛИНСС и ГЛИВС), было присуще воспитание в неполной семье, проживание в одиночестве или неполных семьях, наличие среднего или среднеспециального образования. Клиниконозологическая структура психических расстройств в данных группах различалась в зависимости от пола. У мужчин чаще всего диагностировались расстройства, обусловленные потреблением ПАВ. Среди женщин преобладало расстройство адаптации с нарушением эмоций и поведения. При этом тяжесть депрессивных нарушений была более выраженной в ГЛИВС.

Сравниваемые группы (ГЛИНСС и ГЛИВС) статистически значимо различались по индивидуально-характерологическим особенностям: возбудимости $(p=0,001)$ и выраженности мотивации к совершению суицида $(\mathrm{p}=0,000)$, по способу совершения суицидальной попытки $(\mathrm{p}=0,000)$.

Наиболее значимым фактором, взаимосвязанным с выраженной мотивацией (8 баллов и более) к совершению суицида, был способ суицида $\left(\mathrm{r}_{\mathrm{s}}=-\right.$ $0,68)$. Жизнеопасный способ (самоповешение $85,7 \%$ ) преобладал в ГЛИВС (против 5,4\% случаев в ГЛИНСС). В ГЛИВС отмечались как наиболее травматичные способы самоповреждения, так и наиболее выраженная мотивация к совершению суицида. Это подтверждается данными литературы о наличии различий в способах совершения суицида и парасуицида, ранее многократно освещавшимися в отечественных публикациях $[1,8]$.

Пограничный уровень значимости отмечался для факторов, связанных с наличием психических расстройств $\left(\mathrm{r}_{\mathrm{s}}=0,28\right)$ и уровнем образования $\left(\mathrm{r}_{\mathrm{s}}=-\right.$ 0,28). При анализе полученных данных с учетом показателя половой принадлежности значение факторов изменялось. Для мужчин наиболее значимыми являлись три фактора: способ суицида $\left(r_{s}=-0,68\right)$, темперамент $\left(r_{s}=0,37\right)$ и наличие психического расстройства $\left(\mathrm{r}_{\mathrm{s}}=0,36\right)$. Для женщин значимым фактором с положительной корреляционной взаимосвязью была выраженность депрессии $\left(\mathrm{r}_{\mathrm{s}}=0,36\right)$, к факторам с отрицательной взаимосвязью относились способ совершения суицида $\left(\mathrm{r}_{\mathrm{s}}=-\right.$ $0,58)$ и уровень дохода $\left(\mathrm{r}_{\mathrm{s}}=-0,4\right)$. Пограничный уровень значимости отмечался только в отношении фактора уровень образования $\left(\mathrm{r}_{\mathrm{s}}=-0,28\right)$.
Вместе с тем не было выявлено взаимосвязи между показателем выраженности психосоциального стресса и мотивацией. Статистически значимые межгрупповые отличия по выраженности психосоциального стресса отсутствовали и между исследованными группами. В то же время в ГЛИВС данный показатель был менее выражен (157 [86; 225]), чем в ГС (216 [138; 310]), что может подтверждать значимость индивидуальных особенностей личности при формировании суицидального поведения в ситуации стресса.

Полученное распределение показателей согласуется с моделью стресс-диатеза суицидального поведения, которая утверждает, что суицид является результатом взаимодействия между стрессовыми факторами и индивидуальной предиспозицией к суицидальному поведению [10].

Наличие статистически значимых межгрупповых различий по темпераменту между группами подтверждает данную гипотезу. В ГЛИВС преобладали лица с флегматическим темпераментом, для которых характерны низкая поведенческая активность, трудности в выработке новых стратегий поведения, приверженность к привычным формам поведения, низкая степень гиперактивности и возбудимости, застревание на негативных событиях. Данный фактор у лиц мужского пола был значимо взаимосвязан с мотивацией к суициду $\left(r_{s}=0,37\right)$. Кроме того, у мужчин выделялись индивидуальные особенности личности в виде возбудимости и нейротизма, что свидетельствовало об эмоциональной неустойчивости, повышенной раздражительности и подверженности к импульсивному поведению в ситуации стресса.

У женщин тип темперамента не был значимым фактором, но при этом выделялся фактор выраженности депрессивных нарушений, особенно в ГЛИВС, сочетавшийся с акцентуацией характера по циклотимному типу. Для них характерна быстрая смена настроения, когда подъем сменяется периодом плохого настроения. Это может свидетельствовать о разных психопатологических механизмах, приводящих к формированию суицидального поведения. У женщин - склонность к депрессивным нарушениям, обусловливающим формирование чувства безнадежности, у мужчин - флегматический темперамент с характерным для него застреванием на негативных чувствах и наличие трудностей в решении текущих жизненных проблем, что провоцирует злоупотребление ПАВ и последующее формирование зависимости. Хроническое потребление ПАВ вызывает токсическое повреждение структур головного мозга и приводит к заострению личностных черт, перепадам настроения, импульсивности и агрессивности в поведении, причем нередко направленной на фоне опьянения на собственное «Я». 


\section{ОБСУЖДЕНИЕ}

Настоящее исследование показало, что способ суицида может являться одним из показателей выраженности намерения уйти из жизни, что подтверждает обоснованность выделения NSSI (NonSuicidal Self-Injury - несуицидальное самоповреждение) в DSM-5, для которого характерно преобладание поверхностных повреждений тела острыми предметами (до 70\%) и отсутствие мотивации к самоубийству, что в свое время было отмечено А.Г. Амбрумовой [11].

Данное исследование подтвердило важный вклад психических расстройств в формирование суицидального поведения, что на данный момент не вызывает сомнений [1]. Было установлено участие различных факторов, являющихся причиной формирования психопатологических нарушений в зависимости от пола. У мужчин - это потребление ПАВ, что обусловлено особенностями темперамента и формированием черт личности в виде застревания на чувствах и мыслях, трудностей в выработке новых форм поведения, эмоциональной неустойчивости и повышенной раздражительности. Все указанные факторы существенно затрудняют социальное взаимодействие, провоцируя состояние хронического стресса и дальнейшее потребление ПАВ по типу «порочного круга». У женщин наиболее значимым фактором оказался циклотимический тип акцентуации характера, что проиводило к развитию эмоциональных нарушений депрессивного спектра и подтверждалось наличием статистически значимых различий между степенью выраженности депрессивных нарушений в группах суицидального риска (ГЛИВС и ГЛИНСС) в зависимости от типа суицидального поведения. Следует отметить, что в соответствии с данными психологической аутопсии депрессия обнаруживается у лиц, совершивших суицид, в пределах от $29 \%$ до $88 \%$ [7].

В результате проведенного исследования установлена значимость фактора образования для формирования мотивации к совершению суицида. У лиц женского пола данный фактор отмечался на границе значимости, при этом отмечалась выраженная взаимосвязь мотивации к совершению суицида с фактором дохода (уровень ежемесячного дохода), что может косвенно свидетельствовать о значении интеллектуального развития для предикции суицида. В настоящее время установлено, что школьная успеваемость коррелирует с тестами интеллекта на уровне $\mathrm{r}=0,5$; некоторые авторы отмечают корреляцию показателей, полученных с применением теста Равена, со школьными баллами от 0,3 до 0,72 [12]. Отмечена также корреляция между коэффициентом интеллекта ребенка и его статусом во взрослом возрасте, которая может составлять до $\mathrm{r}=0,8$ [13].
Высокий социальный статус, как правило, взаимосвязан с высоким уровнем дохода, что не характерно для лиц, входящих в группу суицидального риска. Для лиц с высоким интеллектом свойственна также способность к формированию «зрелых» психологических защит, что позволяет более эффективно совладать с негативными эмоциями в состоянии стресса, избегая эффекта «туннельного мышления».

Так, согласно результатам, полученным в ходе настоящего исследования, исследовательские группы статистически значимо не различались по выраженности перенесенного психосоциального стресса, но при этом статистически значимо различались по выраженности мотивации к совершению суицида $(\mathrm{p}=0,00)$. При этом в группах суицидального риска (ГЛИВС и ГЛИНСС) преобладали лица, имеющие среднее или среднеспециальное образование, что согласуется с данными следственного комитета по Гродненской области за 2010-2019 гг. [14] и Минской области за 20152019 гг., которые свидетельствуют о преобладании среди совершивших суицид лиц со средним или базовым образованием.

Как отмечают зарубежные исследователи, индивиды с нехваткой дивергентного мышления испытывают трудности в совладании с неблагоприятными жизненными обстоятельствами, что приводит к формирования чувства безнадежности и в конечном счете к суициду [15]. Поэтому одни лица, воспитанные в неблагоприятных социальных условиях, находясь в ситуации личностного кризиса, не видя выхода из ситуации, решением для себя считают совершение суицида, другие рассматривают кризис личностной идентификации как возможность дальнейшего личностного роста и развития, достигая, таким образом, творческого самовыражения и социального благополучия.

\section{ВЫВОДЫ}

Согласно результатам, полученным в ходе собственного исследования, наиболее выраженным фактором, взаимосвязанным с мотивацией к совершению суицида, был способ самоповреждения. Психические расстройства, у мужчин проявляющиеся чаще всего в форме расстройств, обусловленных потреблением ПАВ, у женщин - эмоциональными нарушениями депрессивного спектра, а также уровень образования у лиц обоего пола имеют пограничный уровень значимости, взаимосвязанный с выраженной мотивацией к совершению суицида.

Социальные условия проживания и индивидуальные особенности личности были значимы для лиц, входящих в группу суицидального риска, но не являлись факторами, взаимосвязанными с выраженной мотивацией к совершению суицида. 


\section{КОНФЛИКТ ИНТЕРЕСОВ}

Представленные в настоящей статье материалы не содержат каких-либо потенциальных или явных конфликтов интересов авторов.

\section{ИСТОЧНИК ФИНАНСИРОВАНИЯ}

Исследование выполнено в рамках темы НИР «Изучить молекулярно-генетические предикторы суицидального поведения с целью разработки диагностических критериев повышенного риска суицида» в рамках выполнения государственной программы научных исследований «Фундаментальные и прикладные науки - медицине» Подпрограмма «Диагностика и терапия заболеваний» на 2016-2020 гг. (номер госрегистрации 20161106 от 11.06.2016 г.).

\section{СООТВЕТСТВИЕ ПРИНЦИПАМ ЭТИКИ}

Опрос пациентов осуществлялся в соответствии с требованиями Хельсинкской декларации BMA «Этические принципы проведения научных медицинских исследований с участием человека». Форма информированного согласия утверждена на заседании комитета по этике ГУО «Белорусская медицинская академия последипломного образования» (протокол № 2 от 13.06.2017 г.)

\section{ЛИТЕРАТУРА}

1. Предотвращение самоубийств: глобальный императив. Женева : ВО3, 2014: 96. http://www.who.int/mental_health/suicide-prevention

2. Игумнов С.А., Гелда А.П. Суицидальное поведение населения в Российской Федерации и Республике Беларусь: динамика за 30-летний период. Неврологический вестник. 2016; XLVIII (4): 30-33. DOI: https://doi.org/10.17816/nb14014

3. Положий Б.С., Игумнов С.А., Ример 3. и др. Суициды в России и Европе / под ред. Б.С. Положего. М.: Медицинское информационное агентство, 2016: 209.

4. Игумнов С.А., Гелда А.П., Осипчик С.И. Система профилактики суицидального поведения: опыт Беларуси. Суицидология. 2016; 7, 2(23): 3-22.

5. Корнетов А.Н. Распространенность и клиникоконституциональные особенности суицидально- го поведения в подростково-юНОшеском возрасте: автореф. дис. ... к.м.н. Томск, 1999: 22.

6. Игумнов С.А., Давидовский С.В. Динамика суицидального поведения жителей Минска. Ученые записки. Человек, алкоголь, курение и пищевые аддикции (соматические и наркопсихиатрические проблемы). Материалы 2-го междисциплинарного Российского конгресса. СПб. : СПбГМУ им. акад. И.П. Павлова, 2008: 138-139.

7. WHO/EURO Multicenter Study on Parasuicide. Facts and figures / Ed. U. Bille-Brache. Copenhagen : World Health Organization Regional Office for Europe, 1999: 99.

8. Давидовский С.В. Особенности суицидального поведения среди жителей г. Минска. Здравоохранение (Минск). 2016; 3: 72-77.

9. Lonnqvist J.K. Psychiatric aspects of suicidal behavior: depression. In: Hawton K., van Heeringen K., eds. The International Handbook of Suicide and Attempted Suicide, New York, NY: Wiley; 2000. DOI: 10.1002/9780470698976.ch7

10. van Heeringen K., Mann J.J. Neurobiology of suicide. Lancet Psychiatry. 2014 Jun;1(1):63-72. doi: 10.1016/S2215-0366(14)70220-2

11. Амбрумова А.Г. Психология самоубийства. Социальная и клиническая психиатрия. 1996; 6(4): 14-20.

12. Дружинин В.Н. Когнитивные способности: структура, диагностика, развитие. М.: Пер Сэ; СПб.: Иматон-М, 2001: 223.

13. Ушаков Д.В. Психология интеллекта и одаренности. М. : Изд-во «Институт психологии РАН», 2011: 464.

14. Букин С.И. Критерии оценки риска суицида. Журнал Гродненского медицинского университета. 2019; 17(5): 530-538. DOI: 10.25298/22218785-2019-17-5-530-537

15. Schotte D., Clum G. Suicide ideation in a college population: A test of a model. Journal of Consulting and Clinical Psychology. 1982; 50: 690-696. https://doi.org/10.1037/0022-006X.50.5.690

Поступила в редакцию 17.06.2020 Утверждена к печати 02.09.2020

Давидовский Сергей Владимирович, к.м.н., доцент кафедры психотерапии и медицинской психологии. 䀂 +375296286726 .

Ибрагимова Жанна Аркадьевна, к.б.н., заведующий лабораторией биохимических методов исследования. 苗 +375297049205. E-mail: lbmibgmu@mail.ru

Игумнов Сергей Александрович, д.м.н., профессор, руководитель отдела клинической наркологии. E-mail: sigumnov67@gmail.com

Костюк Дарья Дмитриевна, аспирант. 푤 +375291666323. E-mail: kostyuk20001402@mail.ru

Мещеряков Юрий Владимирович, старший преподаватель кафедры финансового менеджмента и информатизации здравоохранения.

Стефании Александр Леонидович, доцент кафедры финансового менеджмента и информатизации здравоохранения. E-mail: A.I.Stefanin@gmail.com

$\bowtie$ Давидовский Сергей Владимирович, davidouski@yandex.ru 
For citation: Davidovsky S.V., Ibragimova Zh.A., Igumnov S.A., Kostyuk D.D., Meshcheryakov Yu.V., Stefanin A.L. Clinical-psychological and socio-demographic features of suicidal behavior of the population of Minsk (Republic of Belarus). Siberian Herald of Psychiatry and Addiction Psychiatry. 2020; 3 (108): 102-113. https://doi.org/10.26617/1810-3111-2020-3(108)-102-113

\title{
Clinical-psychological and socio-demographic features of suicidal behavior of the population of Minsk (Republic of Belarus)
}

\section{Davidovsky S.V.1, Ibragimova Zh.A.2, Igumnov S.A.3, Kostyuk D.D.4, Meshcheryakov Yu.V.1, Stefanin A.L.1}

\author{
${ }^{1}$ Belarusian Medical Academy of Postgraduate Education \\ Petrus' Brovka Street 3, Building 3, 220013, Minsk, Republic of Belarus \\ ${ }^{2}$ Belarusian State Medical University \\ Dzerzhinsky Avenue 83, 220116, Minsk, Republic of Belarus \\ ${ }^{3}$ National Scientific Center for Addiction Medicine - Branch of V.P. Serbsky \\ National Medical Research Center of Psychiatry and Narcology \\ Kropotkinsky Lane 23, 119034, Moscow, Russian Federation \\ ${ }^{4}$ Wroclaw State University, Institute of Psychology \\ Universitetskaya Square 1, 50-137, Wroclaw, Poland
}

\begin{abstract}
Background. Currently, the search for reliable indicators of the risk of committing suicide remains relevant, which makes important the study of causes and conditions of the occurrence of suicidal behavior. Objective: to determine statistically significant clinical and psychological factors and socio-demographic characteristics associated with severe motivation to commit suicide. Material and Methods. Based on the data of 10-year monitoring of suicidal behavior of Minsk residents, two groups of individuals with suicide risk are formed from the main group of respondents: 1) a group of persons who have used non-lethal methods of self-harm (conditionally called GPUNS), 2) a group of persons who have used highly lethal methods of self-harm (GPUHS). The comparison group includes persons who have the diagnosis of adjustment disorder (ICD-10 code F43.2), who have not previously committed suicide attempts. Significance for binary indicators is assessed by the Pearson criterion $\left(\chi^{2}\right)$, for quantitative indicators by the Kruskal-Wallis test $(\mathrm{H})$, intergroup differences are assessed by the Mann-Whitney test (U). The relationship between socio-psychological factors and the motivation to commit suicide is determined with the Spearman's correlation coefficient ( $r$ ) using the Python programming language. Results. The most pronounced factor interrelated with the severe motivation to commit suicide has been the way of committing suicide $\left(r_{s}=-0.68\right)$. It is found that the borderline significance level $\left(r_{s}=0.28\right)$ has two factors: 1$)$ the factor of the presence of mental disorders due to alcohol use in men, in women - presence of depression spectrum disorders; 2$)$ the education factor $\left(\mathrm{r}_{\mathrm{s}}=0.28\right)$. Persons from suicide risk groups (GPUHS and GPUNS), are characterized by upbringing in a one-parent family, living alone or in oneparent families, and having a secondary or secondary special education. In GPUHS group, certain personality traits are revealed (excitability in men and cyclothymia in women). Conclusions. The most significant factor associated with severe motivation to commit suicide is the method of suicidal actions. The factor of the presence of the diagnosis of mental disorder and the factor of education are on the border of statistical significance. Social living conditions and individual personality traits are significant factors for suicide risk groups, but are not interrelated with severe motivation to commit suicide.
\end{abstract}

Keywords suicide, parasuicide, indicators of the risk of committing suicide, method of suicide, population of Belarus, Spearman's correlation coefficient.

\section{REFERENCES}

1. Suicide Prevention: a Global Imperative. Geneva: WHO, 2014: 96 (in Russian). http://www.who.int/mental_health/suicide-prevention

2. Igumnov S.A., Gelda A.P. Suicidal behavior of the population in the Russian Federation and the Republic of Belarus: dynamics over a 30 -year period.
Neurological Bulletin. 2016; XLVIII (4): 30-33 (in Russian). DOI: https://doi.org/10.17816/nb14014

3. Polozhy B.S., Igumnov S.A., Rimer Z. et al. Suicides in Russia and Europe / edited by. B.S. Polozhy. Moscow: Medical Information Agency, 2016: 209 (in Russian). 
4. Igumnov S.A., Gelda A.P., Osipchik S.I. The system of prevention of suicidal behavior: the experience of Belarus. Suicidology. 2016; 7, 2(23): 3-22 (in Russian).

5. Kornetov A.N. Prevalence and clinical and constitutional features of suicidal behavior in adolescence: PhD thesis. Tomsk, 1999: 22 (in Russian).

6. Igumnov S.A., Davidovsky S.V. The dynamics of suicidal behavior of Minsk residents. Scholarly notes. Individual, alcohol, smoking and food addiction (somatic and drug-related psychiatric problems). Materials of the $2^{\text {nd }}$ Interdisciplinary Russian Congress. Saint Petersburg: I.P. Pavlov Saint Petersburg State Medical University, 2008: 138-139 (in Russian).

7. WHO/EURO Multicenter Study on Parasuicide. Facts and Figures / Ed. U. Bille-Brache. Copenhagen: World Health Organization Regional Office for Europe, 1999: 99.

8. Davidovsky S.V. Features of suicidal behavior among residents of Minsk. Healthcare (Minsk). 2016; 3: $72-77$ (in Russian).

9. Lonnqvist J.K. Psychiatric aspects of suicidal behavior: depression. In: Hawton K., van Heeringen K., eds. The International Handbook of Suicide and
Attempted Suicide, New York, NY: Wiley; 2000. DOI: 10.1002/9780470698976.ch7

10. van Heeringen K., Mann J.J. Neurobiology of suicide. Lancet Psychiatry. 2014 Jun;1(1):63-72. doi: $10.1016 / \mathrm{S} 2215-0366(14) 70220-2$

11. Ambrumova A.G. The psychology of suicide. Social and Clinical Psychiatry. 1996; 6(4): 14-20 (in Russian).

12. Druzhinin V.N. Cognitive skills: structure, diagnosis, development. Moscow: Publishing House Per Se; St. Petersburg: Publishing House Imaton-M, 2001: 223 (in Russian).

13. Ushakov D.V. Psychology of intelligence and giftedness. Moscow: Publishing House "Institute of Psychology of RAS”, 2011: 464 (in Russian).

14. Bukin S.I. Criteria for assessing the risk of suicide. Journal of Grodno Medical University. 2019; 17(5): 530-538 (in Russian). DOI: 10.25298/2221-87852019-17-5-530-537

15. Schotte D., Clum G. Suicide ideation in a college population: A test of a model. Journal of Consulting and Clinical Psychology. 1982; 50: 690-696. https://doi.org/10.1037/0022-006X.50.5.690

Received June 17.2020 Accepted September 02.2020

Davidovsky Sergey V., PhD, Associate Professor of the Department of Psychotherapy and Medical Psychology, Belarusian Medical Academy of Postgraduate Education, Minsk, Republic of Belarus. 涌 +375296286726.

Ibragimova Zhanna A., PhD, Head of the Laboratory of Biochemical Research Methods, Belarusian State Medical University, Minsk, Republic of Belarus. 疅 +375297049205. E-mail: lbmibgmu@ mail.ru

Igumnov Sergey A., MD, Professor, Head of the Department of Clinical Narcology, National Scientific Center for Addiction Medicine - Branch of V.P. Serbsky National Medical Research Center of Psychiatry and Narcology, Moscow, Russian Federation. E-mail: sigumnov67@gmail.com

Kostyuk Daria D., postgraduate student, Wroclaw State University, Institute of Psychology, Wroclaw, Poland. I푱 +375291666323. E-mail: kostyuk20001402@mail.ru

Meshcheryakov Yuri V., senior lecturer, Department of Financial Management and Health Informatization, Belarusian Medical Academy of Postgraduate Education, Minsk, Republic of Belarus.

Stephanie Alexander L., Associate Professor, Department of Financial Management and Health Informatization, Belarusian Medical Academy of Postgraduate Education, Minsk, Republic of Belarus. E-mail: A.I.Stefanin@gmail.com

$\bowtie$ Davidovsky Sergey V, davidouski@yandex.ru 